\title{
Musics, Cultures and Meanings: Music as Communication
}

\author{
IAN CROSS \\ Centre for Music \& Science, University of Cambridge, UK
}

\begin{abstract}
This commentary explores interpretations of concepts that lie at the focus of Richard Widdess's paper-"music", and "culture"-with the aim of specifying frameworks within which issues of musical meaning can fruitfully be addressed.
\end{abstract}

Submitted 2012 January 6; accepted 2012 July 13.

KEYWORDS: culture language, evolution, communication

RICHARD WIDDESS'S thought-provoking paper in this volume illuminates the idea that meaningand in particular, meaning in music - in culture is best explored in terms of lived experience rather than through verbal enquiry by reference to three specific cultural examples that I suspect we can all recognise as being distinct and as being other. At the same time he relies-I think, quite correctly-on the idea that the same kind of phenomenon, music, is being manifested in each distinct cultural context. It may seem trivial and somewhat truistic even to raise these points, but I think that they can be used to point up some of the issues that I see as being involved in the understanding of meaning in cultural context.

To start where Widdess started, what do we mean by "culture"? I'd suggest that when we seek to explore the nature of musical meaning, this question actually breaks down into two sub-questions: what do we mean by "a culture"? and what do we mean by "culture" per se? We can think of these two questions as reflecting different facets of the concept of culture, one adverting to the dynamics of intracultural processes and the delineation of cultural boundaries, whereas the other addresses the prospectively immanent actuality of supracultural processes.

How can one define "a" culture? Supplementing Tylor's and Bloch's definitions, one can start by suggesting that culture is the particular means by which people have everyday lives, hence a culture is whatever its members think, make, believe, do, and learn amongst each other in order to live their normal, everyday lives. As Widdess points out, the dynamics of a specific culture are best understood through lived experience rather than mediated by linguistic representations. But what precisely determines "a" culture, particularly a musical culture? As a complex example, in the context of Northern Territories Australian aboriginal cultures, as Widdess noted, there are particular musical entities - not works, but songs or specific song-types - and specific contexts of use of these songs that recognisably attach to one or other particular local culture. But members of these cultures also engage with - creating, performing and listening to-other musics such as rock or country music that could suggest that many of these cultures' members have been assimilated into a broader, westernised, Australian musical culture. The determining features of the local musical cultures may seem to be in the process of being obliterated by the juggernaut of global, commercial musical culture, as appears to have occurred in the case of the rich Venda musical culture memorialised by John Blacking (according to Jaco Kruger, 2006). In fact, rather than being obliterated, the musics of some local Australian Aboriginal cultures have been extended, not just in structure but in function; in a self-conscious process of ganma, or "bi-culturalisation", earlier indigenous musical practices still persist while new practices such as heavy rock or reggae - that seem to an outsider to be wholly Western - have been assimilated into the cultural repertoire to be put to local, indigenous uses, as in the case of the Yolyu rock band Yothu Yindi (see Corn, 2010), in this case as a means of re-articulating and sustaining Yolyu culture in its local, national and global context.

Perhaps it is only when a culture is exposed to reflective scrutiny that the issue of what constitutes "a" culture arises in the first place. As Bashkow notes (2004, p. 454), "...cultural boundaries are necessary for thinking and writing about human cultural worlds", but those human cultural worlds-cultures-about which we can write and speak must be understood as neither emically distinct domains nor anthropologically isolable entities but as dynamic constructs engaged in a continual process of mutual refashioning. 
To turn to implications arising from the second question-what do we mean by "culture" per $s e$ ? - how can we understand musical meaning, or even music as a phenomenon that is evident across cultures? Perhaps the prevalent "transcultural", or ostensibly culture-neutral, approach to the general understanding of supra-cultural meaning could be located in the abstract formalisms of model-theoretic semantics (Montague, 1974). However, as Scruton (1987) points out, the apparent absence of consensual referential meaning in music implies that model-theoretic semantics have little relevance here. An alternative might be found within globalisation theory, perhaps in the form of the confluence of "-scapes" - ethno-scapes, media-scapes, techno-scapes, finan-scapes and ideo-scapes_-sketched by Appadurai (1990), where meaning is a contingent and fluctuating outcome of the constitution of the narratives afforded by converging and diverging forces across the "-scapes-scape". But here the openendedness of the framework offers few clues as to how best to situate any meaning that might be specifically demarcated as musical. A further alternative framework might be grounded in evolutionary psychology. Though much of what has been proposed in that domain can be criticised for having imported-implicitly_culture-specific frames of reference into ostensibly universalising theory, my own preference is to locate attempts to triangulate supracultural aspects of music within a framework that is grounded in evolutionary considerations.

Why might one concern oneself with meaning at the supracultural level in the first place? I'd suggest that we have to address this level in order to arrive at ways of understanding meaning that are potentially reconcilable with an understanding of human behaviour (or constraints on human behaviour) at the species level: that is, a biologically-grounded understanding. I stress here that the aim is to reconcile accounts grounded in cultural epistemologies with those rooted in biological accounts, not to reduce the former to the latter.

How can one arrive at the supracultural level, purging accounts of behaviour of emic specificity? One simply can't; there are no clean criteria for identifying the universal in human behaviour, as human behaviours are inextricably entangled in the vicissitudes of cultural life. But one can attempt to define and explore what appears to be the same kinds of thing-behaviours, frames for action and/or interaction - across cultures in order to assess commonalities of structure and function in broad terms (i.e., in terms that may be cross-cultural rather than constrained to local, cultural application), and one can also postulate the existence of suites of behaviours that are essential for survival and reproduction and hence likely to be humanly generic. In the case of language, such commonalities appear self-evident; all human cultures make use of complex communicative systems to exchange information, to coordinate social action and to make sense of the world in terms of collectively-accessible structures. Language is capable of the communication of semanticallydecomposable propositions about states of affairs; it thus provides means of mobilising shared intentionality for goal-directed behaviour.

For music, any such commonalities are much less clear. But across cultures, music appears embedded in social action, and I'd suggest that a generic "something-like-music" constitutes a foundationally non-conflictual medium for communicative interaction. "Something-like-music" affords participants the collective intuition that they "understand" each other. It does so partly by virtue of its floating intentionality - each participant can, within limits, abstract the meanings that they feel are expressed in or reflected by the music, but as music does not require that its meaning be recast back into the public domain in order to be efficacious, individually-constructed "meanings" are not brought into potential conflict.

At the same time, music functions as what Turino (2008) terms a "dicent" index; the acoustical signals that embody it are experienced as though there is a necessary causal connection between their structure and the affective and motivational states of those producing it. This property of music - that it appears to "mean like it sounds", that it seems to be to be an "honest signal"—can be interpreted as deriving from its exploitation of systems that are more-or-less reflexively sensitive to both the biological and the social significances of sounds (and gestures). In addition, music also tends to manifest itself within a framework that is essentially affiliative, one that foregrounds cues that enable participants to align their behaviours with those of each other-cues that enable interpersonal entrainment. Music at the supracultural level appears as a communicative medium optimal for mobilising shared intentionality per se.

From this perspective, language and music appear as close relatives, and meaning in language or in music at the supracultural level may be more a question of degree than of kind. I'd suggest that the boundaries between language and music are probably illusory, and it might be better to think of the terms "music" and "language" as referring to opposite poles on a communicative continuum of specificity and/or consensual determinacy. Of course, this sort of hypothesis at the supracultural level leaves quite unresolved the question of how best to tackle musical meaning in cultural context; it does, however, suggest that common constraints play at least some role in shaping the ways in which musical meaning in culture may be manifested and may be effective. 


\section{REFERENCES}

Appadurai, A. (1990). Disjuncture and Difference in the Global Cultural Economy. Theory Culture Society, Vol. 7, No. 2, pp. 295-310.

Bashkow, I. (2004). A Neo-Boasian Conception of Cultural Boundaries. American Anthropologist, Vol. 106, No. 3, pp. 443-458.

Corn, A. (2010). Land, song, constitution: exploring expressions of ancestral agency, intercultural diplomacy and family legacy in the music of Yothu Yindi with Mandawuy Yunupinu. Popular Music, Vol. 29, No. 1, pp. 81-102.

Kruger, J. (2006). Tracks of the mouse: tonal reinterpretation in Venda guitar sounds. In S. A. Reily (Ed.), The musical human: rethinking John Blacking's ethnomusicology in the twenty-first century. Aldershot: Ashgate, pp. 37-70.

Montague, R. (1974). Formal philosophy: selected papers. New Haven, Connecticut: Yale University Press.

Scruton, R. (1987). Analytical philosophy and the meaning of music. Journal of Aesthetics and Art Criticism, Vol. 46, pp. 169-176.

Turino, T. (2008). Music as social life: the politics of participation. London: University of Chicago Press. 